\title{
Age-Related Deficits of Dual-Task Walking: A Review
}

\author{
Rainer Beurskens and Otmar Bock \\ Institute of Physiology and Anatomy, German Sport University, Am Sportpark Müngersdorf 6, 50933 Cologne, Germany \\ Correspondence should be addressed to Rainer Beurskens, r.beurskens@dshs-koeln.de
}

Received 28 February 2012; Revised 8 May 2012; Accepted 27 May 2012

Academic Editor: Jennifer L. Bizon

Copyright ( 2012 R. Beurskens and O. Bock. This is an open access article distributed under the Creative Commons Attribution License, which permits unrestricted use, distribution, and reproduction in any medium, provided the original work is properly cited.

\begin{abstract}
This review summarizes our present knowledge about elderly people's problems with walking. We highlight the plastic changes in the brain that allow a partial compensation of these age-related deficits and discuss the associated costs and limitations. Experimental evidence for the crucial role of executive functions and working memory is presented, leading us to the hypothesis that it is difficult for seniors to coordinate two streams of visual information, one related to navigation through visually defined space, and the other to a visually demanding second task. This hypothesis predicts that interventions aimed at the efficiency of visuovisual coordination in the elderly will ameliorate their deficits in dual-task walking.
\end{abstract}

\section{Introduction}

Accidental falls in old age are an increasing problem in our graying society, and they have received a lot of attention in recent research. About $30 \%$ of persons aged $65+$ years and about $50 \%$ of those aged $85+$ years fall at least once a year and the probability of falling again increases after each fall [1-3]. Early research addressed environmental hazards, sensorimotor deficits, and impaired balance as risk factors for accidental falls $[4,5]$, but more recent work focuses on the role of cognition $[6,7]$.

According to this recent approach, age-related deficits of locomotion can be partly compensated by cognitive workaround strategies, thus replacing automated sensorimotor processing with effortful higher-order functions. This is a good example of neural plasticity, as it shows that deficits arising in one part of the nervous system can be overcome by engaging another part of that system. Persons with a reduced cognitive capacity have only limited access to this compensation: according to empirical research, they are more likely to walk unsteadily and their risk of falling is higher [8].

Brain plasticity may help overcome the gait problems in old age, but there is a price to pay: cognitive resources allocated to seniors' locomotion are no longer available for other activities while walking, such as obstacle avoidance, navigation along a planned route, watching for pedestrian and vehicular traffic, as well as engaging in gait-unrelated tasks. As a consequence, elderly persons often have larger problems than younger ones to walk and concurrently engage in another activity $[6,7]$.

\section{Anatomical Changes in the Human Brain as a Function of Age}

Early studies in the 1990s were already able to show agerelated changes in the human brain [9-11]. Older people are affected by a general loss of brain mass and a distinctive atrophy of the frontal gray matter, as well as a white matter hyperintensity $[12,13]$. Recent fMRI studies showed a degradation of the cerebral cortex as a function of age. Notably, these studies demonstrated a reduction of gray and white matter in the prefrontal cortex $[14,15]$ and an age-related mass reduction of the frontal lobe $[16,17]$. Additionally, a loss of central neurons and associated synaptic connections accrues, which leads to reduced processing speed and a deficit in the ability to handle several processes simultaneously [18]. Some authors state that these structural changes, especially the changes in white matter in the human brain, are caused by an age-related deterioration of the vascular system and the associated reduction in blood flow [19]. Compared with 
young people, the frontal cortex of people aged $65+$ years is reduced by $10-17 \%$, while the temporal, parietal, and occipital cortices only show a reduction of approximately $1 \%$. This selective shrinkage of the brain seems to affect higher-level cognitive functions $[14,20]$.

Probably most vulnerable to age-related decay are the socalled "executive functions" [13], that is, cognitive operations that include (a) the planning of strategies for different actions, (b) the monitoring of these actions, (c) adjusting future actions using feedback, alertness, and (d) the inhibition of task-irrelevant information [21]. Another agedependent cognitive function is working memory, a set of mechanisms involved in the control, regulation, and active maintenance of task-relevant information in both novel and familiar tasks [22-24]. Executive functions and working memory are both thought to reside [25] in the frontal lobes. Recent experiments evaluated the neural activity in prefrontal brain structures while subjects handled tasks involving executive functions or working memory (e.g., the Wisconsin card sorting test, a self-ordered pointing task, or a delayed-response task) and found that these tasks are sensitive to prefrontal dysfunction [19, 26-28].

Summing up, the available literature suggests that the anatomical decrease of brain mass, especially in the frontal lobe, contributes to a reduction of cognitive processing capacity with advancing age and thus limits to what extent neural plasticity can compensate for age-related decrements of locomotion.

\section{The Role of Cognition in Human Locomotion}

Human walking, a task that people perform on a daily basis, involves complex processes that require the ongoing integration of visual, proprioceptive, and vestibular sensory information. For instance, joint positions have to be controlled, feedback from the terrain the person is walking on has to be integrated, and the environment the person is moving in needs to be observed. In addition, our everyday life affords numerous situations in which walking must be integrated with another activity, such as watching for traffic or using a mobile phone. This concurrence of locomotion and another activity, termed dual-task walking, has received a lot of attention in recent research [29-33]. The human gait pattern is affected by old age. For example, walking speed and stride length decrease, while lateral sway and stride time variability increase with age [34-36]. Some of these changes are compensatory and are used to stabilize posture, while others are dysfunctional and correlate with the risk of accidental falls [5]. The observed deterioration has been attributed to a variety of causal factors, notably to cognitive decline; indeed, the critical role of cognition is supported by the fact that age-related gait changes are more pronounced in people with cognitive impairment $[37,38]$ and that they are accentuated under dual-task conditions $[6,39]$.

The additional tasks utilized in the literature are manifold and range from verbal response and memory tasks to more complex ones such as mathematical tasks or tasks involving visual or motor control. When two or more tasks need to be carried out concurrently, task performance declines at least in one of them. Some studies on dual-task walking found an age-related decrease in dual-task performance when subjects were asked to walk at their preferred walking speed and simultaneously complete another task [39-42], whereas other studies were not able to create this kind of age-related deficit [43-45]. This discrepancy might be due to the utilization of different secondary tasks used in these studies. Some tasks interfere with walking while other tasks do not $[46,47]$. A meta-analysis conducted by AlYahya showed significant increases in age-related deficits while walking when the secondary task was associated with executive or memory functions, for example, verbal fluency tasks or mental imaging but not when the task added was rather simple, for example, reaction or discrimination tasks [48]. This outcome indicates that the central ability to process walking requirements and cognitive demands simultaneously decreases with age, which might arise from insufficient central processing capabilities in older people [49] or from disorders in the coordination of multiple sensory or motor information [50].

3.1. Methodological Issues of Previous Studies. A major problem of many studies on age-related decreases in dualtask performance is the inconsistency of methods. Several studies addressing the influence of cognitive functions on locomotion in the elderly have considerable methodological flaws. For instance, some authors observed a decrease in motor performance under dual-task conditions in seniors but did not relate it to the performance of younger subjects and thus could not ascertain the presence of an age-related decrease $[26,51,52]$. Other studies analyzed walking and disregarded the secondary task, or they focused on secondary task and ignored walking; in consequence, they cannot disambiguate changes of dual-task performance from those of task priority [38, 40, 45, 53]. In principle, concurrent tasks can be given equal or different priorities such as to maximize gains or minimize risks [54]; while young people typically prioritize gait $[55,56]$, older people tend to assign higher priority to the secondary task [30]. As a consequence studies that only evaluate walking will overestimate age-related dualtask deficits, and those that only evaluate the secondary task will underestimate those deficits.

In experiments that considered both tasks and both age groups for their analysis, secondary tasks varied in their sensory demands, in their response requirements, or in their cognitive difficulty. Table 1 shows the mean dualtask costs of young and older subjects taken as examples from recent studies, including the task characteristics of the additional task used. Figure 1 displays the appropriate dualtask costs derived from the same studies. Dual-task costs were determined according to the following formulas:

$$
\mathrm{DTC}=\frac{\mathrm{D}-\mathrm{S}}{\mathrm{S}},
$$

where (D: dual-task performance; $S$ : single task performance), using the mean values of each age group from the studies indicated. 


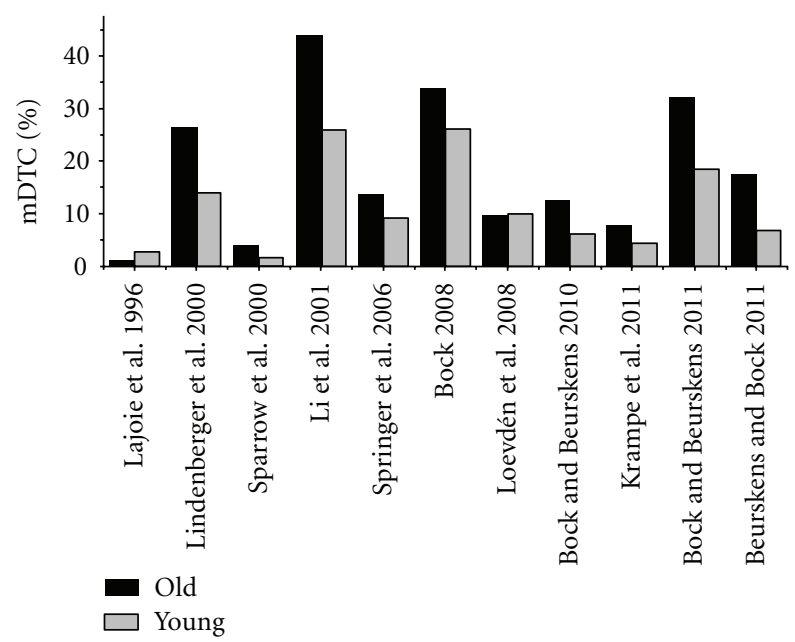

Figure 1: Illustration of mean dual-task costs from different studies evaluating age-related deficits in dual-task walking. Data is calculated from mean values in walking performance and mean values in the secondary tasks used in the studies indicated. Standard errors are not displayed because the data from each individual subject could not be obtained.

To express subjects' dual-task ability irrespective of their individual task priorities, we calculated the dual-task costs across both tasks. The formula used is $[57,58]$

$$
\operatorname{mDTC}=\frac{\mathrm{DTC}(\operatorname{task} \alpha)+\mathrm{DTC}(\operatorname{task} \beta)}{2},
$$

where (task $\alpha$ : walking task; task $\beta$ : additional task).

Thus calculated mean dual-task costs show a subject's decrease in performance when completing two tasks simultaneously instead of one task alone. A high DTC value indicates a poorer performance under dual-task conditions compared with single-task conditions.

As shown in Figure 1, one main difference between all these studies using dual-task paradigms is that different kinds of additional task demands lead to different levels of agerelated dual-task costs ranging from 0.99 to $26.0 \%$ in young persons and from 2.6 to $44.0 \%$ in older aged. Some studies found no deficits of dual-task walking in old age $[29,59,60]$, some observed small deficits $[41,44]$, and others substantial deficits [39, 42, 61-64].

3.2. Studies Using Psychomotor Tasks. The wide divergence of age-related deficits in the above studies suggests that the magnitude of deficits is related to demands of the secondary task. For example, Lajoie et al. evaluated the attentional requirements for maintaining posture and walking in eight young and eight older subjects [29]. They combined a sitting, a standing, and a walking task with a verbal response task where reaction times were measured. Subjects were asked to give a verbal response (top) to an auditory stimulus consisting of a $100 \mathrm{~Hz}$ tone presented for 50 milliseconds. Observation of the auditory task was conducted either in isolation or in combination with subjects walking along a path at their preferred walking speed. The outcome of this study showed a decline in reaction times and a decrease in walking speed in both age groups. Similar results were observed by Sparrow et al. (2006), who investigated the effects of age on treadmill walking while performing a reaction time task [59]. Subjects had to walk at their preferred walking speed on a treadmill and were instructed to press a hand-held response button as soon as a letter was presented on a monitor in front of them. In single and dual-task condition, the mean walking speed of the young group was significantly faster than the walking speed of the older group, and the reaction times in both groups decreased while treadmill walking. These results suggest that completing psychomotor tasks while walking, irrespective of whether the response is verbal or manual, does not seem to be sensitive or challenging enough to give rise to age-related deficits in dual-task performance.

3.3. Studies Using Arithmetic and Memory Tasks. Springer and colleagues evaluated the possible age-related effects of tasks requiring executive functions on human walking [44]. They combined walking with three different tasks: (a) listening to and remembering a simple text, (b) listening to and remembering a complex text, and (c) serial subtracting of seven, starting from 500. Moreover, this study subdivided the older group into "fallers" (one or more fall in the previous six months) and "nonfallers" (no fall in the previous six months). The results identified no age-related effect of dual-task walking when the young group and the older nonfallers were compared. The decrease in walking speed and in secondary task performance was similar. In contrast, when the fallers were compared with the young group, especially with regard to the arithmetic tasks, agerelated deficits in dual-task behavior were clearly observable (dual-task costs: old: 14\%; young: 9\%). The simultaneous processing of arithmetic tasks (subtracting serial 7s) and its cognitive load while walking seems to destabilize the gait of elderly fallers but appears to have no effect in older nonfallers and young people.

A further approach to evaluate the effects of cognitive load and memory function on dual-task walking was conducted by Loevdén and colleagues [60]. They manipulated working memory load using an n-back task while the subject was treadmill walking. Their paradigm showed that cognitive processes used to solve n-back tasks are not related to the control of human locomotion. The extent of agerelated dual-task deficit did not differ between the older and the young people. Just like psychomotor speed, working memory, measured by n-back tasks, does not appear to be a factor in age-related deficits. In addition to that Krampe et al. evaluated the impact of a semantic word fluency task on walking at a fast pace [41]. Subjects were asked to name as many words as possible related to a given category (e.g., "vehicles" or "instruments"). The results indicated a decrease in walking speed for all age groups and this decrease was approximately $3.5 \%$ larger in the older group.

3.4. Studies Using Visually Demanding Tasks. Recent studies that found a substantial increase of dual-task costs with advancing age were conducted by the groups of 
TABLE 1: Summary of main characteristics of the studies included in this review.

\begin{tabular}{|c|c|c|c|c|c|c|c|}
\hline \multirow{2}{*}{ Reference } & \multirow{2}{*}{ Groups } & \multicolumn{2}{|c|}{ mDTC (\%) } & \multicolumn{2}{|c|}{ Dual-tasks } & \multirow{2}{*}{ Outcome } & \multirow{2}{*}{ Significance } \\
\hline & & Young & Older & Walking task & Secondary task & & \\
\hline Lajoie et al. 1996 [29] & $\begin{array}{c}\text { young: } n=8 \\
(26.0 \pm 4.2 \mathrm{y}) \\
\text { old: } n=8 \\
(71.0 \pm 4.2 \mathrm{y})\end{array}$ & 0.99 & 2.63 & normal pace walking & $\begin{array}{l}\text { manual task: } \\
\text { reaction time }\end{array}$ & velocity $(\mathrm{m} / \mathrm{s})$ & n.s. \\
\hline $\begin{array}{l}\text { Lindenberger et al. } \\
2000[39]\end{array}$ & $\begin{array}{c}\text { young: } n=47 \\
(24.0 \pm 3.2 \mathrm{y}) \\
\text { middle: } n=45 \\
(45.0 \pm 3.3 \mathrm{y}) \\
\text { old: } n=48 \\
(65.0 \pm 3.1 \mathrm{y})\end{array}$ & 14.0 & 26.5 & $\begin{array}{c}\text { normal pace walking } \\
\text { (straight and curved } \\
\text { narrow path) }\end{array}$ & $\begin{array}{l}\text { visuospatial } \\
\text { decision task }\end{array}$ & velocity $(\mathrm{m} / \mathrm{s})$ & $* *$ \\
\hline $\begin{array}{l}\text { Sparrow et al. } 2006 \\
\text { [59] }\end{array}$ & $\begin{array}{c}\text { young: } n=10 \\
(26.3 \mathrm{y}) \\
\text { old: } n=10 \\
(71.1 \mathrm{y})\end{array}$ & 1.51 & 3.94 & $\begin{array}{l}\text { normal pace walking } \\
\text { on a treadmill }\end{array}$ & $\begin{array}{l}\text { manual task: } \\
\text { reaction time }\end{array}$ & velocity $(\mathrm{m} / \mathrm{s})$ & n.s. \\
\hline Li et al. 2001 [42] & $\begin{array}{c}\text { young: } n=37 \\
(25.1 \pm 2.7 \mathrm{y}) \\
\text { old: } n=40 \\
(65.6 \pm 3.9 \mathrm{y})\end{array}$ & 26.0 & 44.0 & $\begin{array}{l}\text { normal pace walking } \\
\text { (wide path) }\end{array}$ & $\begin{array}{l}\text { visuospatial } \\
\text { decision task }\end{array}$ & velocity $(\mathrm{m} / \mathrm{s})$ & $* * *$ \\
\hline $\begin{array}{l}\text { Springer et al. } 2006 \\
{[44]}\end{array}$ & $\begin{array}{c}\text { young: } n=19 \\
(29.4 \pm 4.4 \mathrm{y}) \\
\text { fallers: } n=17 \\
(76.1 \pm 4.8 \mathrm{y}) \\
\text { non-fallers: } n=24 \\
(71.0 \pm 5.9 \mathrm{y})\end{array}$ & 9.25 & 13.61 & normal pace walking & $\begin{array}{l}\text { arithmetic task: } \\
\text { counting } \\
\text { backwards by } 7\end{array}$ & velocity $(\mathrm{m} / \mathrm{s})$ & n.s. \\
\hline Bock 2008 [57] & $\begin{array}{c}\text { young: } n=18 \\
(24.3 \pm 3.5 \mathrm{y}) \\
\text { old: } n=15 \\
(67.2 \pm 3.6 \mathrm{y})\end{array}$ & 26.0 & 34.0 & $\begin{array}{l}\text { normal pace walking } \\
\quad \text { (narrow path) }\end{array}$ & $\begin{array}{l}\text { manual task: } \\
\text { checking }\end{array}$ & velocity $(\mathrm{m} / \mathrm{s})$ & $* * *$ \\
\hline $\begin{array}{l}\text { Loevdén et al. } 2008 \\
\text { [60] }\end{array}$ & $\begin{array}{c}\text { young: } n=32 \\
(25.0 \pm 2.9 \mathrm{y}) \\
\text { old: } n=32 \\
(73.6 \pm 2.9 \mathrm{y})\end{array}$ & 9.93 & 9.64 & $\begin{array}{l}\text { slow and normal pace } \\
\text { walking (wide path) }\end{array}$ & $\begin{array}{l}\text { arithmetic task: } \\
\text { counting } \\
\text { backwards by } 1-4\end{array}$ & velocity SD (m/s) & n.s. \\
\hline $\begin{array}{l}\text { Bock and Beurskens } \\
2011[63]\end{array}$ & $\begin{array}{c}\text { young: } n=15 \\
(25.4 \pm 2.9 \mathrm{y}) \\
\text { old: } n=15 \\
(69.2 \pm 4.7 \mathrm{y})\end{array}$ & 6.01 & 12.46 & $\begin{array}{l}\text { normal pace walking } \\
\text { (narrow path) }\end{array}$ & $\begin{array}{l}\text { manual task: } \\
\text { checking }\end{array}$ & velocity $(\mathrm{m} / \mathrm{s})$ & $* * *$ \\
\hline Krampe et al. 2011 [41] & $\begin{array}{c}\text { young: } n=30 \\
(24.3 \pm 2.2 \mathrm{y}) \\
\text { old: } n=30 \\
(64.2 \pm 2.4 \mathrm{y})\end{array}$ & 4.25 & 7.75 & $\begin{array}{l}\text { normal pace walking } \\
\quad \text { (narrow path) }\end{array}$ & $\begin{array}{l}\text { verbal task: } \\
\text { word fluency }\end{array}$ & missteps (\%) & * \\
\hline $\begin{array}{l}\text { Bock and Beurskens } \\
2011 \text { [64] }\end{array}$ & $\begin{array}{c}\text { young: } n=12 \\
(25.6 \pm 2.8 \mathrm{y}) \\
\text { old: } n=12 \\
(68.1 \pm 4.2 \mathrm{y})\end{array}$ & 18.38 & 32.28 & $\begin{array}{l}\text { normal pace walking } \\
\text { (wide path) }\end{array}$ & $\begin{array}{l}\text { visuospatial } \\
\text { decision task }\end{array}$ & step duration (s) & $* * *$ \\
\hline $\begin{array}{l}\text { Beurskens and Bock } \\
2011[61]\end{array}$ & $\begin{array}{c}\text { young: } n=14 \\
(22.0 \pm 2.1 \mathrm{y}) \\
\text { old: } n=14 \\
(69.1 \pm 3.4 \mathrm{y})\end{array}$ & 6.84 & 17.41 & $\begin{array}{l}\text { normal pace walking } \\
\text { (narrow path) }\end{array}$ & $\begin{array}{l}\text { visuospatial } \\
\text { reading task }\end{array}$ & velocity $(\mathrm{m} / \mathrm{s})$ & $*$ \\
\hline
\end{tabular}

Lindenberger et al. $[39,42]$ and Bock and Beurskens [61$64]$. In the studies of the former group, subjects were given a visual memory task where words had to be memorized, and later reproduced, using visuo-spatial imagery. Both studies found higher dual-task costs in the older group compared with younger people, accounted for by the memory task but not by the walking task. The age-related increase of dualtask costs amounted to about $15 \%$, which is higher than 
that in most other studies. Thus, the additional task used by the Lindenberger group seems to be particularly sensitive to age-related deficits in cognitive performance. Bock and colleagues tested this assumption explicitly by systematically investigating the influence of task characteristics on dualtask walking to find out which aspect of a task is responsible for the development of age-related deficits in dual-task conditions [65]. The authors compared the single- and dualtask gait of young and elderly subjects with eight different combinations of walking and nonwalking tasks, and they found age-related deficits of dual-task walking for some but not for other task combinations. Subjects either had to spell words of 18 to 21 letters, remember sequences of different symbols (triangle, cross, ellipse, etc.), close buttons of nine different shapes and sizes on a jacket, accomplish a reaction time task, walk at maximum speed or on wide/narrow paths, walk on a treadmill, or avoid obstacles that were presented on a treadmill at irregular intervals. All these conditions were administered in single- and in dual-task conditions. Bock and colleagues found that dual-task costs were small in most experiments and did not differ between young and older participants. The only task combination in which dual-task performance was distinctly lower in older than in young subjects were experiments requiring the time-critical processing of visual information (e.g., obstacle avoidance in cooperation with a visual reaction time task). Tasks showing the highest deficits in the elderly combined three main features: (a) the task was conducted on a treadmill, (b) subjects had to avoid obstacles, and (c) the walking and nonwalking tasks required continuous visual control. In a second study, Bock explored the effects of the different walking tasks by comparing walking on a treadmill with walking in a hallway [57]. The results from both experiments were similar, overground and treadmill walking had similar effects on age-related dual-task decrements. This outcome leads to the suggestion that walking on a treadmill does not produce deficits in walking as a function of age.

Furthermore, subjects completed walking with two different additional tasks while avoiding obstacles. One secondary task required visual control (i.e., checking boxes on a sheet of paper) and the other tasks required memory and attention resources (i.e., memorizing pictures). In these task combinations, obstacles did not give rise to any age-related deficits, and only the features of the secondary task led to age-related differences in dual-task performance. An increase in dual-task costs occurred mainly in a task requiring visual processing of information and managing two streams of visual information, one related to the checking task and the other one related to the walking task. These results are indirectly supported by a correlation of postural control and the degree of visual impairment that was found by Jamet and colleagues [66]. Beurskens and Bock extended the outcomes of Bock and colleagues and showed that the visual component of a secondary task has a crucial influence on age-related deficits in dual-task walking [61, 64]. The age-related increase of dual-task costs in their studies amounted to about $9 \%$, which is higher than in most other studies but lower than in Lindenberger's experiments $[39,42]$.
3.5. Digression to Studies Using Brief Distractor Tasks Instead of Continuous Ones. In contrast to the methods and tasks used in most of the presented studies, secondary tasks in our everyday life are hardly continuous, and they do not occupy a person for an extended period of time. Usually, the tasks are rather brief, occur rarely and at unpredictable times, for example, stepping over wet spots on the street, watching street signs to work out the right direction or stopping to walk when a car approaches. To consider these kinds of situations, Beurskens and Bock recently compared young and older people's walking behavior after short and unexpected distractions [64]. Eight monitors were arranged at irregular intervals on a straight floor, four to the subject's left, and four to the right. Participants walked the path ten times back and forth at their preferred speed, thus covering a total distance of $400 \mathrm{~m}$ and passing 160 times in front of a monitor. On twelve of those passes, they heard the command "left" or "right," referring to the location of the upcoming monitor. At the same time, a capital letter from the Latin alphabet (such as "G" or " $K$ ") was displayed for 2 seconds on that monitor. Letters were presented mirror-reversed or nonreversed, at a rotation angle of $\pm 60 \%$ or $\pm 120^{\circ}$ with respect to the vertical. Subjects were instructed to respond to each letter by saying "yes" if it was mirror-reversed, and "no" if it was not reversed. Results showed that brief distractions did not influence younger people's walking but significantly changed older people's walking behavior by increasing step duration and decreasing the amplitude of a step [64]. The age-related decrease in dual-task performance reached up to $14 \%$, which is comparable to Lindenberger's findings with visual imagery. Brief visual distracters, therefore, can be as disruptive for elderly persons as an ongoing demand on visual working memory.

\section{Additional Factors Influencing Dual-Task Walking Performance}

In addition to age-related cognitive disorders and a deterioration of cognitive functions with advancing age, there are other potential causes of changes in walking behavior and human locomotion. One further aspect often addressed in contemporary literature is the possible correlation of older people's fear of falling with gait changes. Some authors find correlations and state that the development of fear after a fall leads to changes in walking speed, step time, or the appropriate variability, which leads to recurrent falls during the following years $[32,67,68]$. However, other authors find no evidence that preceding falls increase the occurrence of subsequent falls $[69,70]$ and cannot show that the fear of falling is associated with a reduction of physical activity for safety reasons [71]. In fact, the correlation of psychological functions and human walking is a multidimensional construct where several aspects, ranging from fear of falling, education, physical activity and stress, have to be taken into consideration.

Another possible confounding factor in this area of research is the role of eye movements. Subjects typically focus both their gaze $[72,73]$ and their attention on the goal 
of their activities $[74,75]$, which indicates that attention, eye and body movements are all closely interlinked. However, oculomotor behavior changes with advancing age: the latency and duration of saccades increase while their accuracy decreases, thus necessitating more corrective and refixation saccades [76-78]. Such deficits could complicate the navigation through visually defined space and its integration with another visual task, and thus contribute to impaired dual-task walking.

Yet another factor to be considered is the age-related shrinkage of the attention window, which can be observed not only with cognitive tasks $[79,80]$ but also with manual ones [62]: bimanual tracking deteriorates with display distance in older, but not in young subjects. However, the magnitude of this deterioration in a given elderly person is not related to that person's dual-task costs when walking with a concurrent visuospatial task $\left(R^{2}=0.04 ; P<0.05\right)$, which suggests that peripheral visual attention may not be an important factor in dual-task walking.

\section{Conclusions and Outlook}

When reviewing contemporary research on dual-task walking, motor control, and the role of cognitive functions, the topics of executive functions, and the role of the human frontal lobe have often been addressed. Many studies associate the occurrence of dual-task deficits in the elderly while walking with the well-known decay of prefrontal cortical circuitry, the loss of prefrontal brain mass, and the associated deterioration of executive functions in old age $[16,20,81]$. The current review shows that such deficits are observable mainly with nonwalking tasks requiring substantial visual processing, and thus with the coordination of two independent visual streams of information. It is quite conceivable that this coordination depends critically on higher-level cognitive functions, such as executive functions and working memory, while peripheral visual attention does not seem to play a predominant role. This would fit well with Norman and Shallice's concept of executive control [82], according to which shifts of attention from one task to another take place in a high-level "supervisory attentional system."

That being said, we must add that not all age-related deficits of dual-task walking can be explained by interference between two visual streams. Deficits have also been reported for tasks without a visual component, although they were much smaller than those for tasks having a visual demand $[29,41,59]$ or were limited to very old subjects (75+ years). It, therefore, appears that interference is not necessarily confined to the visual modality but rather can be intermodal, and increasingly so in very old age.

Summing up, we suggest that neural plasticity can partly compensate for age-related deficits of walking: it supplements deteriorated sensorimotor processes by cognitive processes. However, this compensation reduces the cognitive capacity available for concurrent tasks, and is limited by the age-related decay of the prefrontal cortex.

\section{Authors' Contribution}

Both authors have read and concur with the content in the final manuscript. The material within has not been and will not be submitted for publication elsewhere except as an abstract. R. Beurskens has made substantial contributions to all aspects of the submitted work, and the O. Bock to (1) the conception and design of the review, (2) revising the article critically for important intellectual content, and (3) final approval of the version to be submitted.

\section{Conflict of Interests}

The authors declare that they have no conflict of interest.

\section{References}

[1] A. J. Campbell, J. Reinken, B. C. Allan, and G. S. Martinez, "Falls in old age: a study of frequency and related clinical factors," Age and Ageing, vol. 10, no. 4, pp. 264-270, 1981.

[2] M. C. Nevitt, S. R. Cummings, S. Kidd, and D. Black, "Risk factors for recurrent nonsyncopal falls. A prospective study," The Journal of the American Medical Association, vol. 261, no. 18, pp. 2663-2668, 1989.

[3] S. S. Rao, "Prevention of falls in older patients," American Family Physician, vol. 72, no. 1, pp. 81-88, 2005.

[4] G. F. Fuller, "Falls in the elderly," American Family Physician, vol. 61, no. 7, pp. 2159-2168, 2000.

[5] B. E. Maki, "Gait changes in older adults: predictors of falls or indicators of fear?" Journal of the American Geriatrics Society, vol. 45, no. 3, pp. 313-320, 1997.

[6] L. Lundin-Olsson, L. Nyberg, and Y. Gustafson, "'Stops walking when talking' as a predictor of falls in elderly people," The Lancet, vol. 349, no. 9052, p. 617, 1997.

[7] M. Woollacott and A. Shumway-Cook, "Attention and the control of posture and gait: a review of an emerging area of research," Gait and Posture, vol. 16, no. 1, pp. 1-14, 2002.

[8] J. Downton, "Falls in the elderly," in Wenn alte Menschen Stürzen: Ursachen und Risiko; Pflege und Präventio, Ernst Reinhardt, Munich, Germany, 1995.

[9] T. Suhara, H. Fukuda, O. Inoue et al., "Age-related changes in human D1 dopamine receptors measured by positron emission tomography," Psychopharmacology, vol. 103, no. 1, pp. 41-45, 1991.

[10] H. Haug and R. Eggers, "Morphometry of the human cortex cerebri and corpus striatum during aging," Neurobiology of Aging, vol. 12, no. 4, pp. 336-338, 1991.

[11] F. N. Dempster, "Inhibitory processes: a negleted dimension of intelligence," Intelligence, vol. 15, no. 2, pp. 157-173, 1991.

[12] C. W. Nordahl, C. Ranganath, A. P. Yonelinas, C. DeCarli, E. Fletcher, and W. J. Jagust, "White matter changes compromise prefrontal cortex function in healthy elderly individuals," Journal of Cognitive Neuroscience, vol. 18, no. 3, pp. 418-429, 2006.

[13] F. M. Gunning-Dixon and N. Raz, "Neuroanatomical correlates of selected executive functions in middle-aged and older adults: a prospective MRI study," Neuropsychologia, vol. 41, no. 14, pp. 1929-1941, 2003.

[14] N. Raz, "Aging of the brain and its impact on cognitive performance: integration of structural and functional findings," in The Handbook of Aging and Cognition, F. Craik and T. Salthouse, Eds., pp. 1-90, Erlbaum, 2000. 
[15] N. Raz, F. M. Gunning, D. Head et al., "Selective aging of the human cerebral cortex observed in vivo: differential vulnerability of the prefrontal gray matter," Cerebral Cortex, vol. 7, no. 3, pp. 268-282, 1997.

[16] N. Raz, U. Lindenberger, K. M. Rodrigue et al., "Regional brain changes in aging healthy adults: general trends, individual differences and modifiers," Cerebral Cortex, vol. 15, no. 11, pp. 1676-1689, 2005.

[17] D. C. Park and P. Reuter-Lorenz, "The adaptive brain: aging and neurocognitive scaffolding," Annual Review of Psychology, vol. 60, pp. 173-196, 2009.

[18] C. L. Grady and F. I. Craik, "Changes in memory processing with age," Current Opinion in Neurobiology, vol. 10, no. 2, pp. 224-231, 2000.

[19] R. L. Buckner, "Memory and executive function in aging and ad: multiple factors that cause decline and reserve factors that compensate," Neuron, vol. 44, no. 1, pp. 195-208, 2004.

[20] M. G. Rhodes, "Age-related differences in performance on the Wisconsin card sorting test: a meta-analytic review," Psychology and Aging, vol. 19, no. 3, pp. 482-494, 2004.

[21] P. Rabbitt, "Introduction: methodologies and models in the study of executive function," in Methodology of Frontal and Executive Function, P. Rabbitt, Ed., pp. 1-38, Psychology Press, Hove, UK, 1997.

[22] A. Miyake and P. Shah, "Toward unified theories of working memory: emerging general consensus, unresolved theoretical issues, and future research directions," in Models of Working Memory: Mechanisms of Active Maintenance and Executive Control, A. Miyake and P. Shah, Eds., pp. 442-483, Cambridge University Press, Cambridge, Mass, USA, 1999.

[23] A. Baddeley, "Working memory: looking back and looking forward," Nature Reviews Neuroscience, vol. 4, no. 10, pp. 829839, 2003.

[24] A. D. Baddeley, "Is working memory still working?" American Psychologist, vol. 56, no. 11, pp. 851-864, 2001.

[25] J. Jonides, C. Marshuetz, E. E. Smith, P. A. Reuter-Lorenz, R. A. Koeppe, and A. Hartley, "Age differences in behavior and PET activation reveal differences in interference resolution in verbal working memory," Journal of Cognitive Neuroscience, vol. 12, no. 1, pp. 188-196, 2000.

[26] G. Allali, R. W. Kressig, F. Assal, F. R. Herrmann, V. Dubost, and $\mathrm{O}$. Beauchet, "Changes in gait while backward counting in demented older adults with frontal lobe dysfunction," Gait and Posture, vol. 26, no. 4, pp. 572-576, 2007.

[27] D. Head and M. Isom, "Age effects on wayfinding and route learning skills," Behavioural Brain Research, vol. 209, no. 1, pp. 49-58, 2010.

[28] R. L. West, "An application of prefrontal cortex function theory to cognitive aging," Psychological Bulletin, vol. 120, no. 2, pp. 272-292, 1996.

[29] Y. Lajoie, N. Teasdale, C. Bard, and M. Fleury, "Upright standing and gait: are there changes in attentional requirements related to normal aging?" Experimental Aging Research, vol. 22, no. 2, pp. 185-198, 1996.

[30] O. Beauchet, V. Dubost, G. Allali, R. Gonthier, F. R. Hermann, and R. W. Kressig, "Faster counting while walking' as a predictor of falls in older adults," Age and Ageing, vol. 36, no. 4, pp. 418-423, 2007.

[31] V. Dubost, R. W. Kressig, R. Gonthier et al., "Relationships between dual-task related changes in stride velocity and stride time variability in healthy older adults," Human Movement Science, vol. 25, no. 3, pp. 372-382, 2006.
[32] R. W. Kressig, F. R. Herrmann, R. Grandjean, J. P. Michel, and O. Beauchet, "Gait variability while dual-tasking: fall predictor in older inpatients?" Aging-Clinical and Experimental Research, vol. 20, no. 2, pp. 123-130, 2008.

[33] M. B. Neider, J. G. Gaspar, J. S. McCarley, J. A. Crowell, H. Kaczmarski, and A. F. Kramer, "Walking and talking: dual-task effects on street crossing behavior in older adults," Psychology and Aging, vol. 26, no. 2, pp. 260-268, 2011.

[34] R. J. Elble, S. S. Thomas, C. Higgins, and J. Colliver, "Stride-dependent changes in gait of older people," Journal of Neurology, vol. 238, no. 1, pp. 1-5, 1991.

[35] P. M. Mills and R. S. Barrett, "Swing phase mechanics of healthy young and elderly men," Human Movement Science, vol. 20, no. 4-5, pp. 427-446, 2001.

[36] D. A. Winter, A. E. Patla, J. S. Frank, and S. E. Walt, "Biomechanical walking pattern changes in the fit and healthy elderly," Physical Therapy, vol. 70, no. 6, pp. 340-347, 1990.

[37] J. Hausdorff, H. K. Edelberg, S. L. Mitchell, A. L. Goldberger, and J. Y. Wei, "Increased gait unsteadiness in communitydwelling elderly fallers," Archives of Physical Medicine and Rehabilitation, vol. 78, no. 3, pp. 278-283, 1997.

[38] R. Holtzer, J. Verghese, X. Xue, and R. B. Lipton, “Cognitive processes related to gait velocity: results from the Einstein aging study," Neuropsychology, vol. 20, no. 2, pp. 215-223, 2006.

[39] U. Lindenberger, M. Marsiske, and P. B. Baltes, "Memorizing while walking: increase in dual-task costs from young adulthood to old age," Psychology and Aging, vol. 15, no. 3, pp. 417436, 2000.

[40] A. W. Priest, K. B. Salamon, and J. H. Hollman, "Age-related differences in dual task walking: a cross sectional study," Journal of NeuroEngineering and Rehabilitation, vol. 5, article 29, 2008.

[41] R. T. Krampe, S. Schaefer, U. Lindenberger, and P. B. Baltes, "Lifespan changes in multi-tasking: concurrent walking and memory search in children, young, and older adults," Gait and Posture, vol. 33, no. 3, pp. 401-405, 2011.

[42] K. Z. H. Li, U. Lindenberger, A. M. Freund, and P. B. Baltes, "Walking while memorizing: age-related differences in compensatory behavior," Psychological Science, vol. 12, no. 3, pp. 230-237, 2001.

[43] G. Yogev-Seligmann, Y. Rotem-Galili, A. Mirelman, R. Dickstein, N. Giladi, and J. M. Hausdorff, "How does explicit prioritization alter walking during dual-task performance? Effects of age and sex on gait speed and variability," Physical Therapy, vol. 90, no. 2, pp. 177-186, 2010.

[44] S. Springer, N. Giladi, C. Peretz, G. Yogev, E. S. Simon, and J. M. Hausdorff, "Dual-tasking effects on gait variability: the role of aging, falls, and executive function," Movement Disorders, vol. 21, no. 7, pp. 950-957, 2006.

[45] U. Granacher, S. A. Bridenbaugh, T. Muehlbauer, A. Wehrle, and R. W. Kressig, "Age-related effects on postural control under multi-task conditions," Gerontology, vol. 57, no. 3, pp. 247-255, 2011.

[46] C. D. Hall, K. V. Echt, S. L. Wolf, and W. A. Rogers, "Cognitive and motor mechanisms underlying older adults' ability to divide attention while walking," Physical Therapy, vol. 91, no. 7, pp. 1039-1050, 2011.

[47] P. Plummer-D’Amato, L. J. P. Altmann, and K. Reilly, “Dualtask effects of spontaneous speech and executive function on gait in aging: exaggerated effects in slow walkers," Gait and Posture, vol. 33, no. 2, pp. 233-237, 2011. 
[48] E. Al-Yahya, H. Dawes, L. Smith, A. Dennis, K. Howells, and J. Cockburn, "Cognitive motor interference while walking: a systematic review and meta-analysis," Neuroscience and Biobehavioral Reviews, vol. 35, no. 3, pp. 715-728, 2011.

[49] D. Navon and D. Gopher, "On the economy of the humanprocessing system," Psychological Review, vol. 86, no. 3, pp. 214-255, 1979.

[50] H. Pashler, "Shifting visual attention and selecting motor responses: distinct attentional mechanisms," Journal of Experimental Psychology: Human Perception and Performance, vol. 17, no. 4, pp. 1023-1040, 1991.

[51] M. A. Schrager, V. E. Kelly, R. Price, L. Ferrucci, and A. Shumway-Cook, "The effects of age on medio-lateral stability during normal and narrow base walking," Gait and Posture, vol. 28 , no. 3, pp. 466-471, 2008.

[52] V. Dubost, C. Annweiler, K. Aminian, B. Najafi, F. R. Herrmann, and O. Beauchet, "Stride-to-stride variability while enumerating animal names among healthy young adults: result of stride velocity or effect of attention-demanding task?" Gait and Posture, vol. 27, no. 1, pp. 138-143, 2008.

[53] J. M. Hausdorff, A. Schweiger, T. Herman, G. YogevSeligmann, and N. Giladi, "Dual-task decrements in gait: contributing factors among healthy older adults," Journals of Gerontology, vol. 63, no. 12, pp. 1335-1343, 2008.

[54] G. Yogev-Seligmann, J. M. Hausdorff, and N. Giladi, "The role of executive function and attention in gait," Movement Disorders, vol. 23, no. 3, pp. 329-342, 2008.

[55] B. R. Bloem, Y. A. M. Grimbergen, J. G. van Dijk, and M. Munneke, "The "posture second" strategy: a review of wrong priorities in Parkinson's disease," Journal of the Neurological Sciences, vol. 248, no. 1-2, pp. 196-204, 2006.

[56] B. R. Bloem, V. V. Valkenburg, M. Slabbekoorn, and J. G. van Dijk, "The multiple tasks test. Strategies in Parkinson's disease," Experimental Brain Research, vol. 137, no. 3-4, pp. 478-486, 2001.

[57] O. Bock, "Dual-task costs while walking increase in old age for some, but not for other tasks: an experimental study of healthy young and elderly persons," Journal of NeuroEngineering and Rehabilitation, vol. 5, article 27, 2008.

[58] J. M. McDowd and F. I. M. Craik, "Effects of aging and task difficulty on divided attention performance," Journal of Experimental Psychology: Human Perception and Performance, vol. 14, no. 2, pp. 267-280, 1988.

[59] W. A. Sparrow, R. K. Begg, and S. Parker, "Aging effects on visual reaction time in a single task condition and when treadmill walking," Motor Control, vol. 10, no. 3, pp. 201-211, 2006.

[60] M. Loevdén, S. Schaefer, A. E. Pohlmeyer, and U. Lindenberger, "Walking variability and working-memory load in aging: a dual-process account relating cognitive control to motor control performance," The Journals of Gerontology, vol. 63, no. 3, pp. 121-128, 2008.

[61] R. Beurskens and O. Bock, "Role of motor skills and visual demand for age-related deficits in dual-task walking," Ageing Research, vol. 2, no. 1, 2011.

[62] R. Beurskens and O. Bock, "Age-related decline of peripheral visual processing: the role of eye movements," Experimental Brain Research, vol. 217, no. 1, pp. 117-124, 2011.

[63] O. Bock and R. Beurskens, "Age-related deficits of dual-task walking: the role of foot vision," Gait and Posture, vol. 33, no. 2, pp. 190-194, 2011.
[64] O. Bock and R. Beurskens, "Effect of visual distractors on the gait of elderly versus young persons," Current Gerontology and Geriatrics Research, vol. 2011, Article ID 651718, 7 pages, 2011.

[65] O. Bock, K. Engelhard, P. Guardiera, H. Allmer, and J. Kleinert, "Gerontechnology and human cognition," IEEE Engineering in Medicine and Biology Magazine, vol. 27, no. 4, pp. 23-28, 2008.

[66] M. Jamet, D. Deviterne, G. C. Gauchard, G. Vançon, and P. P. Perrin, "Higher visual dependency increases balance control perturbation during cognitive task fulfilment in elderly people," Neuroscience Letters, vol. 359, no. 1-2, pp. 6164, 2004.

[67] O. Beauchet, G. Allali, C. Annweiler et al., "Does change in gait while counting backward predict the occurrence of a first fall in older adults?" Gerontology, vol. 54, no. 4, pp. 217-223, 2008.

[68] O. Beauchet, C. Annweiler, G. Allali, G. Berrut, F. R. Herrmann, and V. Dubost, "Recurrent falls and dual task-related decrease in walking speed: is there a relationship?" Journal of the American Geriatrics Society, vol. 56, no. 7, pp. 1265-1269, 2008.

[69] J. Vaillant, P. Martigné, N. Vuillerme et al., "Prediction of falls with performance on timed "up-and-go" and one-leg-balance tests and additional cognitive tasks," Annales de Readaptation et de Medecine Physique, vol. 49, no. 1, pp. 1-7, 2006.

[70] P. A. Stalenhoef, J. P. M. Diederiks, J. A. Knottnerus, A. D. M. Kester, and H. F. J. M. Crebolder, "A risk model for the prediction of recurrent falls in community-dwelling elderly: a prospective cohort study," Journal of Clinical Epidemiology, vol. 55, no. 11, pp. 1088-1094, 2002.

[71] G. A. R. Zijlstra, J. C. M. van Haastregt, J. T. M. van Eijk, E. van Rossum, P. A. Stalenhoef, and G. I. J. M. Kempen, "Prevalence and correlates of fear of falling, and associated avoidance of activity in the general population of community-living older people," Age and Ageing, vol. 36, no. 3, pp. 304-309, 2007.

[72] J. Pelz, M. Hayhoe, and R. Loeber, "The coordination of eye, head, and hand movements in a natural task," Experimental Brain Research, vol. 139, no. 4, pp. 266-277, 2001.

[73] M. Hayhoe, B. Gillam, K. Chajka, and E. Vecellio, "The role of binocular vision in walking," Visual Neuroscience, vol. 26, no. 1, pp. 73-80, 2009.

[74] M. M. Hayhoe, A. Shrivastava, R. Mruczek, and J. B. Pelz, "Visual memory and motor planning in a natural task," Journal of Vision, vol. 3, no. 1, pp. 49-63, 2003.

[75] N. Mennie, M. Hayhoe, and B. Sullivan, "Look-ahead fixations: anticipatory eye movements in natural tasks," Experimental Brain Research, vol. 179, no. 3, pp. 427-442, 2007.

[76] C. Paquette and J. Fung, "Old age affects gaze and postural coordination," Gait and Posture, vol. 33, no. 2, pp. 227-232, 2011.

[77] E. L. Irving, M. J. Steinbach, L. Lillakas, R. J. Babu, and N. Hutchings, "Horizontal saccade dynamics across the human life span," Investigative Ophthalmology and Visual Science, vol. 47, no. 6, pp. 2478-2484, 2006.

[78] M. Meza, P. Patterson, and H. Nakayasu, "Comparing visual performance and useful field of view of older and younger drivers," Biomedical Sciences Instrumentation, vol. 45, pp. 83$88,2009$.

[79] K. K. Ball, B. L. Beard, D. L. Roenker, R. L. Miller, and D. S. Griggs, "Age and visual search: expanding the useful field of view," Journal of the Optical Society of America A, vol. 5, no. 12, pp. 2210-2219, 1988.

[80] J. Edwards, L. A. Ross, V. G. Wadley, O. J. Clay, M. Crowe et al., "The useful field of view test: normative data for older adults," Archives of Clinical Neuropsychology, vol. 21, no. 4, pp. 275286, 2006. 
[81] D. Head, "Differential vulnerability of anterior white matter in nondemented aging with minimal acceleration in dementia of the Alzheimer type: evidence from diffusion tensor imaging," Cerebral Cortex, vol. 14, no. 4, pp. 410-423, 2004.

[82] D. A. Norman and T. Shallice, "Attention to action: willed and automatic control of behaviour," in Consciousness and SelfRegulation, R. J. Davidson, G.E. Schwartz, D. Shapiro et al., Eds., Plenum, New York, NY, USA, 1986. 

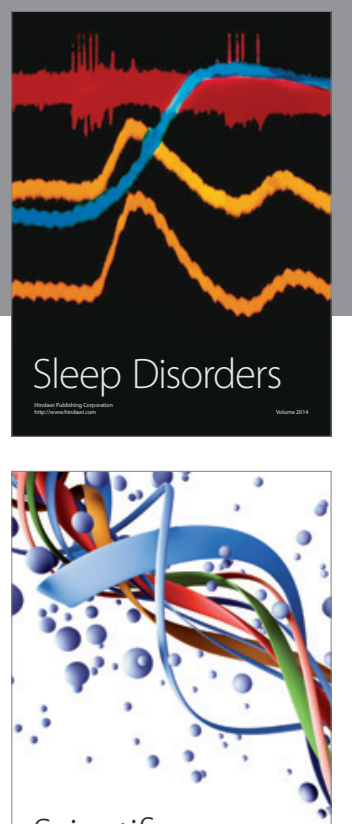

Scientifica
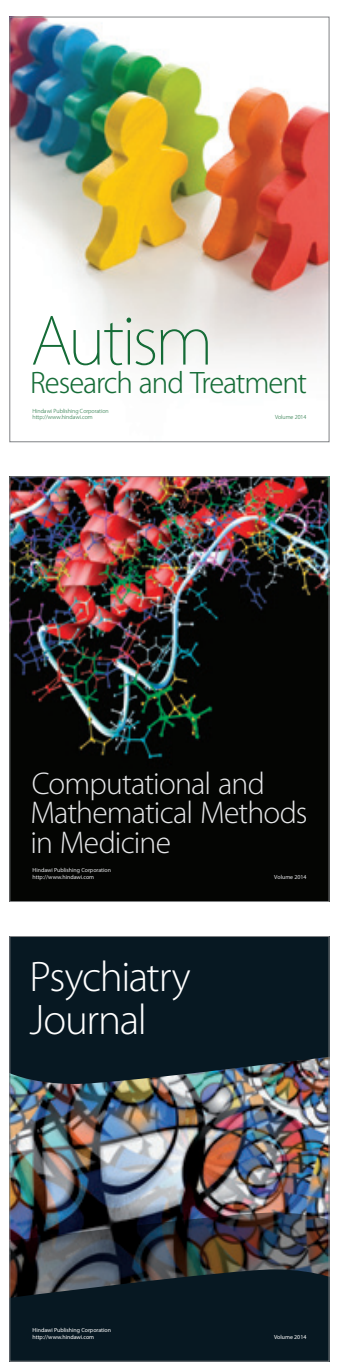
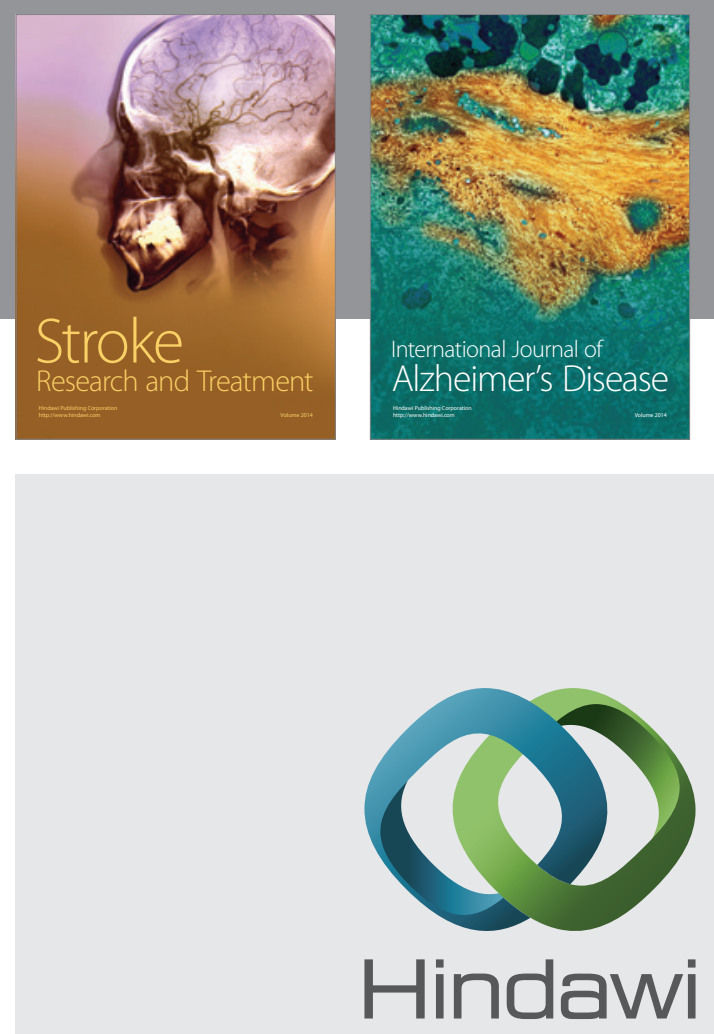

Submit your manuscripts at

http://www.hindawi.com
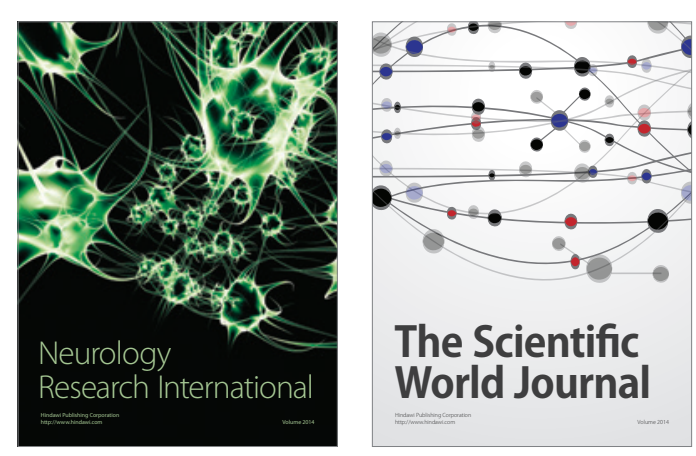

The Scientific World Journal

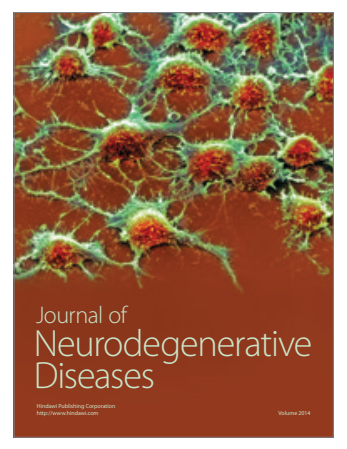

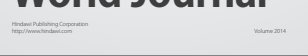

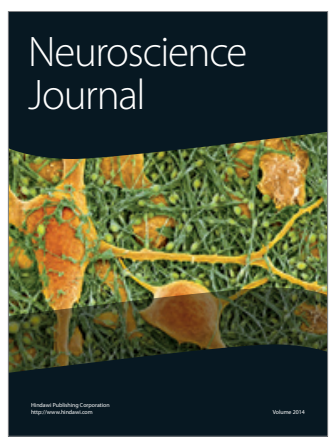

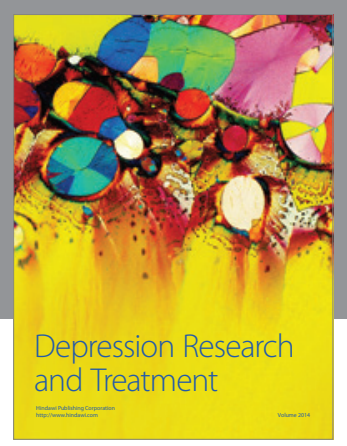
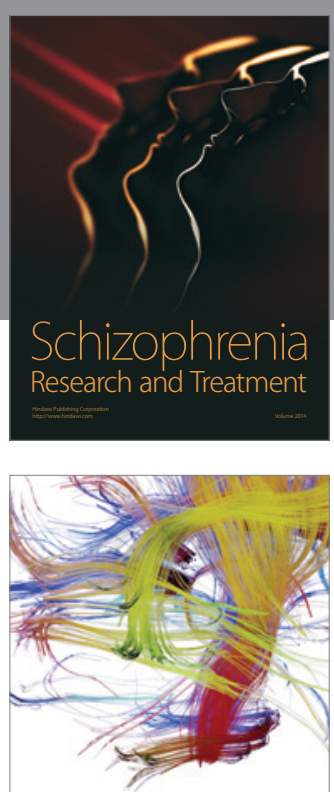

Brain Science

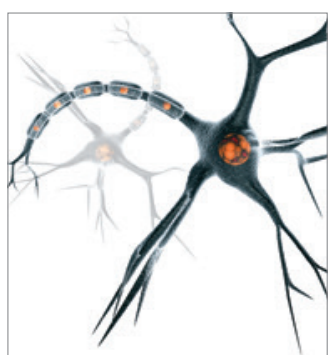

Neural Plasticity
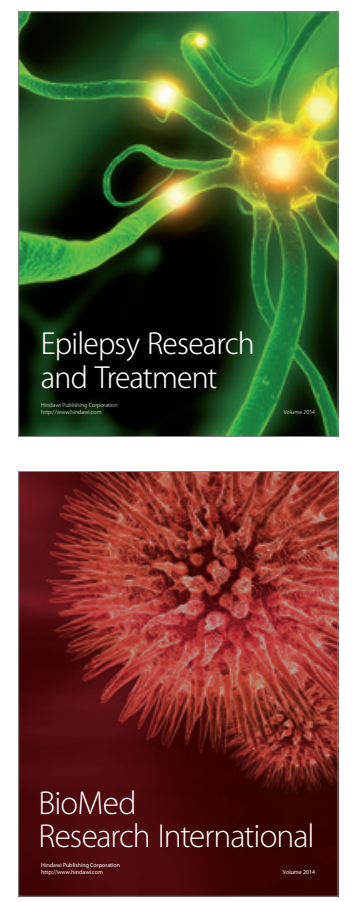

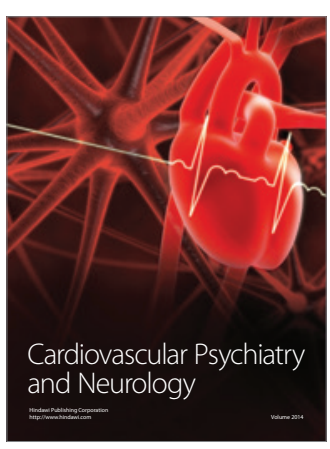

Parkinson's

Disease
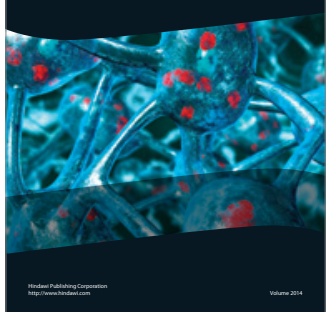